TITLE:

\title{
Experimental study on system stability evaluation in parallel running of a superconducting generator and a SMES
}

\author{
AUTHOR(S):
}

Shirai, Y; Nitta, T; Yamada, A

\section{CITATION:}

Shirai, Y ... [et al]. Experimental study on system stability evaluation in parallel running of a superconducting generator and a SMES. IEEE TRANSACTIONS ON APPLIED

SUPERCONDUCTIVITY 2002, 12(1): 890-895

ISSUE DATE:

2002-03

URL:

http://hdl.handle.net/2433/50258

\section{RIGHT:}

(c)2002 IEEE. Personal use of this material is permitted. However, permission to reprint/republish this material for advertising or promotional purposes or for creating new collective works for resale or redistribution to servers or lists, or to reuse any copyrighted component of this work in other works must be obtained from the IEEE. 


\title{
Experimental Study on System Stability Evaluation in Parallel Running of a Superconducting Generator and a SMES
}

\author{
Y. Shirai, T. Nitta, and M. Yamada
}

\begin{abstract}
Parallel running operation of $100 \mathrm{kVA}$ Superconducting Generator (SCG) with high response excitation and 0.4 MJ SMES (Superconducting Magnet Energy Storage) was carried out. The exciter capacity of the high response excitation is rather large compared with that of conventional generators. The exciter controller, that is, AVR (Automatic Voltage Regulator) and PSS (Power System Stabilizer) are designed taking the exciter power change at the excitation into account to improve the system stability. The SMES can also improve the power system stability. The SMES can give the small active power modulation of sinusoidal wave to the system. The system responses due to the SMES power modulation were observed and analyzed in order to evaluate the designed control functions of AVR, PSS and SMES. Frequency characteristics of the designed control functions were obtained from on-line data of the system. The system stability of parallel running of the SCG and the SMES was evaluated by use of SMES power control.
\end{abstract}

Index Terms-Excitation control, power system stability, SMES, superconducting generator.

\section{INTRODUCTION}

$\mathbf{S}$ UPERCONDUCTING Generators (SCGs) have many advantages such as small size, weight, high efficiency and so on. Many studies have been done on SCGs [1]-[3]. They can improve power system stability in steady states and also in transient states with high response excitation. An experimental $100 \mathrm{kVA}$ SCG with high response excitation whose pet name is Hesper 1 was designed and made. Several experiments for power system stability using an artificial transmission line were carried out [4]-[6]. A 1.2 MJ Superconducting Magnet Energy Storage (SMES) unit of toroidal magnet type (three module magnets) was designed and made by KEPCO, Japan. Basic tests were carried out and it was confirmed that the SMES has good feature in power system stabilization control [7]. We proposed a new usage of SMES, that is, on-line diagnosis of power system operating conditions by use of SMES [8]. The SMES, which is installed for power system stabilization, for example, can give a

\footnotetext{
Manuscript received September 24, 2001. This work was supported in part by the Japan Society for the Promotion of Science under Project JSPS-RFTF97P01004.

Y. Shirai is with the Department of Energy Science and Technology, Kyoto University, Yoshida-Honmachi, Sakyo-ku, Kyoto, 606-8501 Japan (e-mail: shirai@energy.kyoto-u.ac.jp).

T. Nitta is with the Department of Electrical Engineering, the University of Tokyo, 7-3-1, Hongo, Bunkyo-ku, Tokyo, 113-8656 Japan (e-mail: nitta@asc.t.u-tokyo.ac.jp).

M. Yamada is with Kansai Electric Power Company, Nakohji, Amagasaki-shi, Hyogo, Japan (e-mail: K431639@kepco.co.jp).

Publisher Item Identifier S 1051-8223(02)03848-4.
}

TABLE I

RATINGS AND MACHINE CONSTANTS OF HESPER 1

\begin{tabular}{|c|c|c|}
\hline \multicolumn{3}{|l|}{ specifications } \\
\hline rated capacity & \multicolumn{2}{|c|}{$100(\mathrm{kVA})$} \\
\hline rated voltage & \multicolumn{2}{|c|}{$220(\mathrm{~V})$} \\
\hline rated current & \multicolumn{2}{|c|}{ 263(A) } \\
\hline rated field voltage & \multicolumn{2}{|c|}{$2(\mathrm{~V})$} \\
\hline rated field current & \multicolumn{2}{|c|}{$140(\mathrm{~A})$} \\
\hline rated power factor & \multicolumn{2}{|c|}{0.9 (lag.) } \\
\hline rated speed & \multicolumn{2}{|c|}{$1800(\mathrm{rpm})$} \\
\hline pole & \multicolumn{2}{|c|}{4 (poles) } \\
\hline phase & \multicolumn{2}{|l|}{3} \\
\hline ceiling voltage & \multicolumn{2}{|c|}{$120(V)$} \\
\hline \multicolumn{3}{|l|}{ machine constants } \\
\hline synchronous reactance & $\mathrm{Xd}$ & 0.34 (p.u.) \\
\hline d-axis transient reactance & $\mathrm{Xd}^{\prime}$ & 0.32 (p.u.) \\
\hline d-axis subtransient reactance & $\mathrm{Xd}$ & 0.20 (p.u.) \\
\hline negative-phase-sequence reactance & $\mathrm{X} 2$ & 0.20 (p.u.) \\
\hline open-circuit time constant & Tdo' & $80(\mathrm{sec})$ \\
\hline open-circuit subtransient time constant & Tdo" & $0.02(\mathrm{sec})$ \\
\hline field inductance & Lf & $1.14(\mathrm{H})$ \\
\hline
\end{tabular}

TABLE II

SPECIFICATION OF SUPERCONDUCTING MAGNET OF SMES

\begin{tabular}{ll}
\hline ratings & \\
\hline rated capacity & $422 \mathrm{~kJ}$ \\
rated voltage & $400 \mathrm{~V}$ \\
rated current & $350 \mathrm{~A}$ \\
inductance & $6.89 \mathrm{H}$ \\
material of superconductor & $\mathrm{NbTi}$ \\
\hline
\end{tabular}

small continuous power disturbance of known pattern (such as a sinusoidal wave) with very small influence on power system. By monitoring the small power oscillation of line powers or generator output powers due to the SMES power change, a dynamic stability characteristic of the system is evaluated [8].

In this paper, $100 \mathrm{kVA}$ SCG with high response excitation and infinite bus system including 0.4 MJ SMES (one of three toroidal modules is used) is considered. The system stability of parallel running of the SCG and the SMES is evaluated by use of SMES power control unit. The field coil of SCG with high response excitation is one of a pulse coil of a certain stored energy. Therefore the exciter controller, that is, AVR (Automatic Voltage Regulator) and PSS (Power System Stabilizer) should be designed taking the exciter power change at the excitation into account in order to improve the system stability. The SMES 


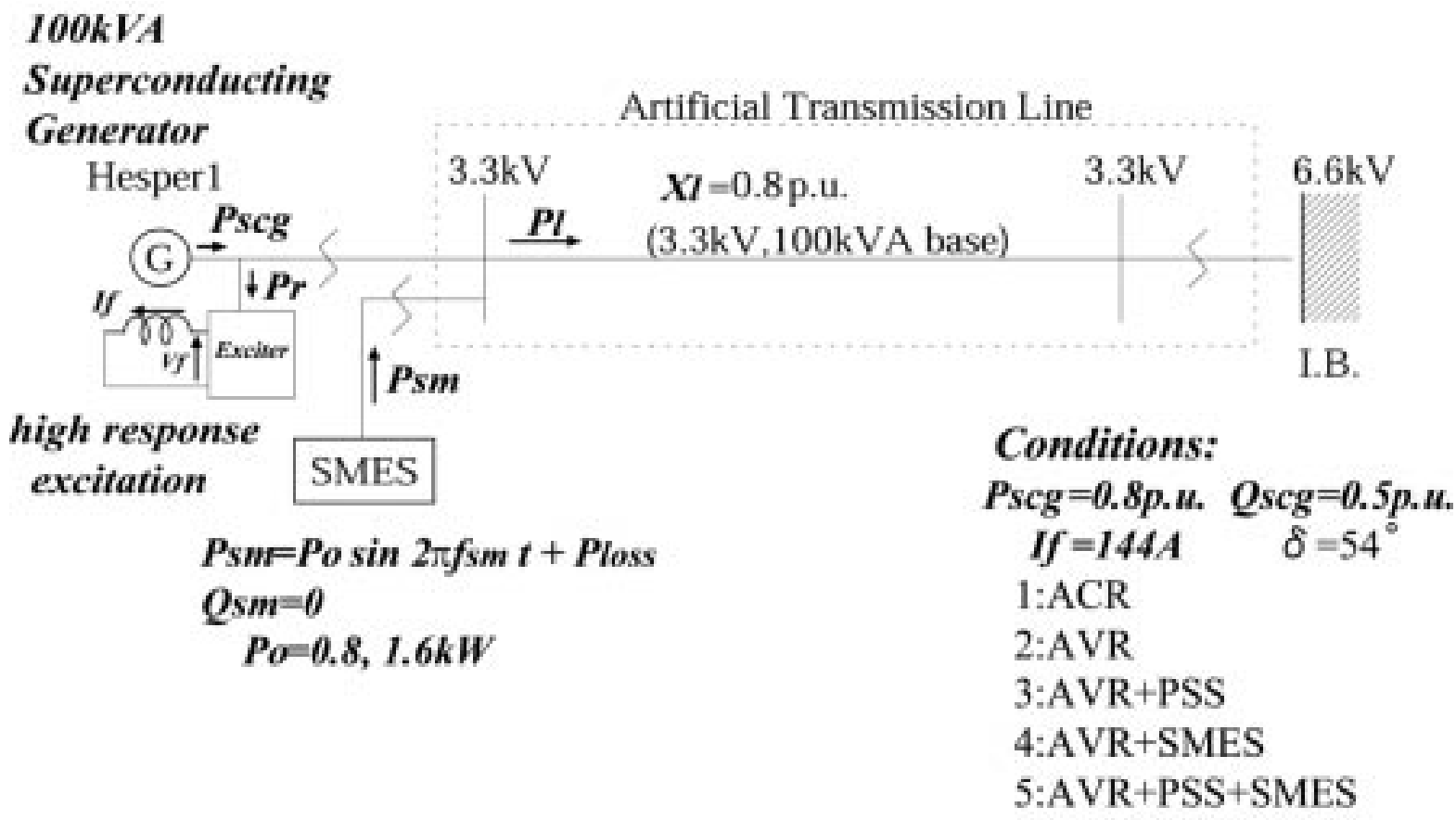

Fig. 2. Experimental system and conditions.

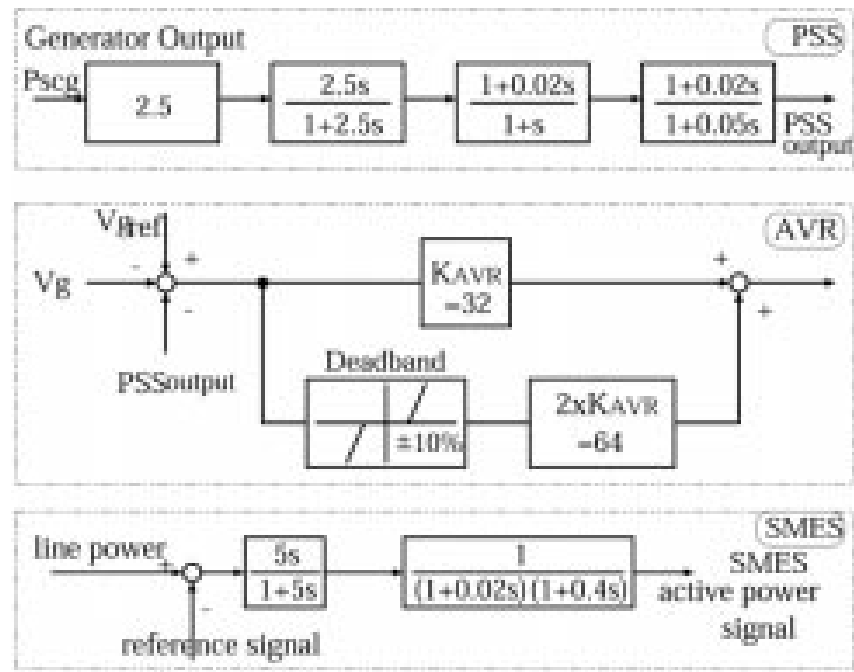

Fig. 1. Block diagram of exciter control (AVR and PSS) and power system stabilization control of SMES.

can also improve the power system stability. The designed control function of AVR, PSS and SMES are evaluated by use of SMES power control.

\section{EXPERIMENTAL SYSTEM}

\section{A. SCG With High Response Excitation Control and SMES}

1) Experimental SCG (Hesper 1): The $100 \mathrm{kVA}$ SCG (Hesper 1) was designed and manufactured so that the high response excitation is possible. The specification of Hesper 1 is shown in Table I. The rated capacity and the rated voltage of Hesper 1, that is, $100 \mathrm{kVA}$ and $220 \mathrm{~V}$, respectively, are the base values of per unit. The ceiling voltage is determined to be 120 $\mathrm{V}$ (60 p.u.) so that the magnetic flux linkage of air gap would

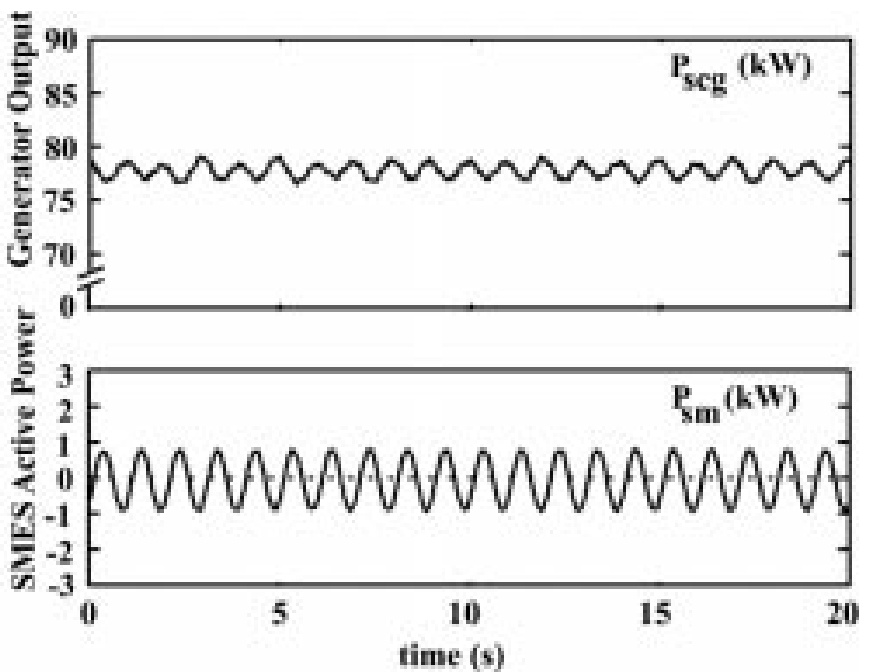

Fig. 3. SMES power disturbance $\left(P_{0}=0.8 \mathrm{~kW}, f_{s m}=1 \mathrm{~Hz}\right)$ and the generator power.

be identical to that of large capacity SCGs designed by some feasibility studies. The superconducting field magnet is made of $\mathrm{NbTi}$ wire and designed for high response excitation.

2) SMES System: 1.4 MJ toroidal type SMES unit consists of three modules. One of the three modules was used for the experiment. Specification of the superconducting magnet of SMES is shown in Table II. Inverter and chopper system is applied to AC/DC/converter. The rated capacity, AC rated voltage, DC rated voltage of inverter are $20 \mathrm{kVA}, 200 \mathrm{~V}$ and $400 \mathrm{~V}$, respectively. The rated voltage and current of the chopper are $400 \mathrm{~V}$ and $350 \mathrm{~A}$.

3) Exciter for SCG With High Response Excitation: The time constant $T_{d o}^{\prime}$ of SCG is very large compared with that of the conventional generator [6]. Therefore, the capacity of the 


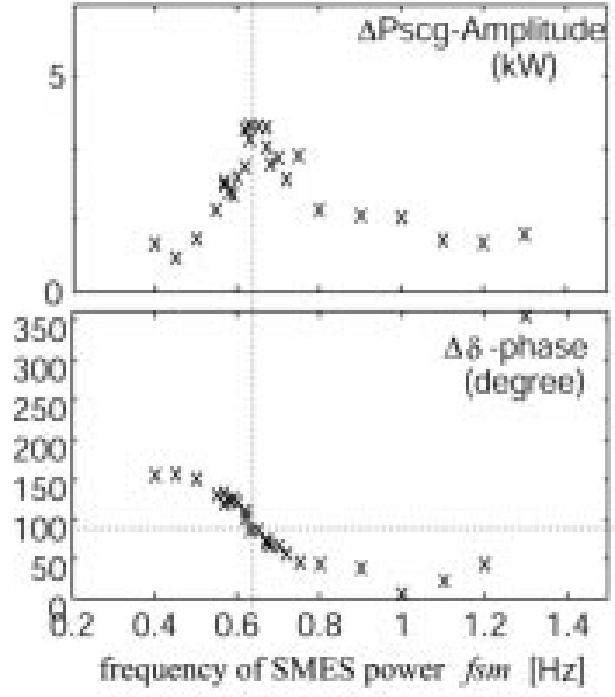

(a) with ACR

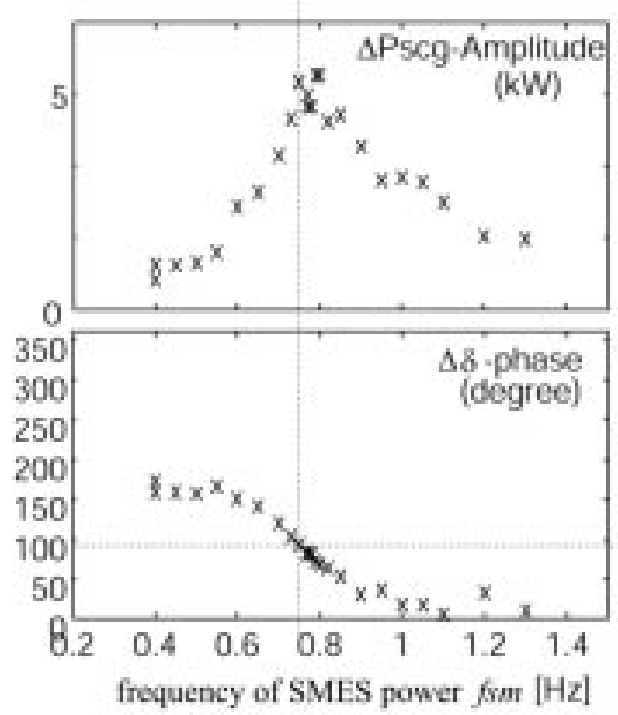

(b) with AVR

Fig. 4. Frequency characteristics of the generator power swing with $[\mathrm{ACR}]$ and $[\mathrm{AVR}]$ controls.

exciter for SCGs with high response excitation becomes larger than that for the conventional machine. The exciter power at quick change of the field current is large enough to affect the power system stability in a self-excited operation in which the exciter is connected to the generator terminal. The exciter power should be taken into account in the design of the exciter control (AVR and PSS). The thyristorized exciter is used. It is controlled by a digital automatic voltage regulator (AVR) system, whose block diagram is shown in Fig. 1.

The AVR gain of SCG with high response excitation must be larger than that of conventional generator because of the large time constant $T_{d o}^{\prime}$. In the steady state operations, however, the large AVR gain reduces the power system stability margin. Therefore, PSS (Power System Stabilizer) is necessary and AVR function has dead-band to switch the gain from $K_{A V R}=32$ for small disturbances to $2 \times K_{A V R}$ for large disturbances [5].

\section{B. Experimental System}

The experimental power system is shown in Fig. 2. The system is considered to be a one-machine infinite bus system. Output power of $100 \mathrm{kVA}$ SCG flows through the transmission line to $6.6 \mathrm{kV}$ power source (assumed as the infinite bus). The 0.4 MJ SMES is installed at the generator terminal.

The transmission line reactance is 0.8 p.u. $(3.3 \mathrm{kV}, 100 \mathrm{kVA}$ base). The output power of SCG is 0.8 p.u. $(80 \mathrm{~kW})$. The field current is $144 \mathrm{~A}$. The operating cases of the exciter and the SMES are set as follows:

1) [ACR (Constant field current control)]

2) [AVR (Automatic Voltage Regulation Control)]

3) $[$ AVR + PSS (Power System Stabilization control)]

4) [AVR with SMES stabilizing control]

5) $[$ AVR + PSS with SMES stabilizing control].

With these operating cases, the frequency characteristics of these stabilizing control systems are evaluated on-line by use of SMES power modulation. The small power disturbance is given to the system from SMES. The active power $P_{s m}$ of SMES is changed according to the sinusoidal signal

$$
P_{s m}=P_{0} \sin \left(2 \pi f_{s m} t\right)+P_{l o s s}
$$

where $P_{0}$ is the amplitude of the power change $(0.8$ and $1.6 \mathrm{~kW})$, $f_{s m}$ is the frequency of the power change (from 0.4 to $1.3 \mathrm{~Hz}$ ) and $P_{l o s s}$ is the loss of SMES, while the reactive power $Q_{s m}$ of SMES is $0 \mathrm{kVar}$. The power system responses of the small continuous disturbances are observed as shown in Fig. 3, for example. The generator output $P_{s c g}$ contains small oscillation of amplitude $=1 \mathrm{~kW}$ around $78 \mathrm{~kW}$ due to the SMES power modulation of $0.8 \mathrm{~kW}$ amplitude.

The amplitude and the phase of the deviation $\Delta P_{s c g}$ of generator power, the deviation $\Delta \delta$ of the rotor angle, the deviation $\Delta P_{r}$ of the exciter power, the PSS control signal, the SMES stabilizing control signal $P_{s t a b}$ are obtained by Fourier Transformation for various frequencies $f_{s m}$ of the SMES power change.

\section{EXPERIMENTAL RESULTS}

\section{A. Difference Between ACR and AVR Control}

The frequency characteristics of the power oscillation due to the small SMES power disturbance with [ACR] and [AVR] control are shown in Fig. 4(a) and (b), respectively. The amplitude of $\Delta P_{s c g}$ has peak value $(4 \mathrm{~kW})$ at the frequency of $0.62 \mathrm{~Hz}$ with ACR control when the phase of the deviation $\Delta \delta$ of the rotor angle (base phase: $P_{s m}$ ) is 90 degrees.

The frequency of $0.62 \mathrm{~Hz}$ is considered to be the natural frequency of the system. The natural frequency of the system with AVR-control is $0.75 \mathrm{~Hz}$ and the peak value of $\Delta P_{s c g}$ is $5.5 \mathrm{~kW}$. As the natural frequency is higher, the synchronizing force of the generator becomes larger. It can be said that the AVR-control increases the synchronous force, but reduces the damping force. 


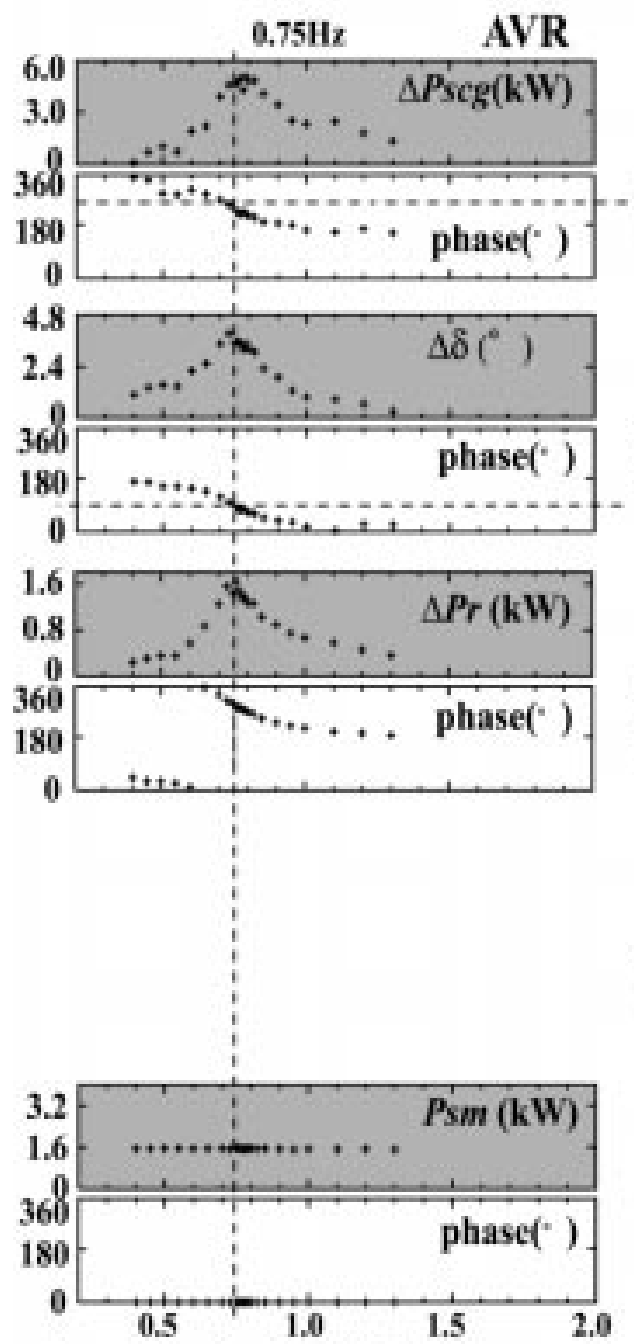

Frequency $f \mathrm{sm}$ of SMES active power $(\mathrm{Hz})$
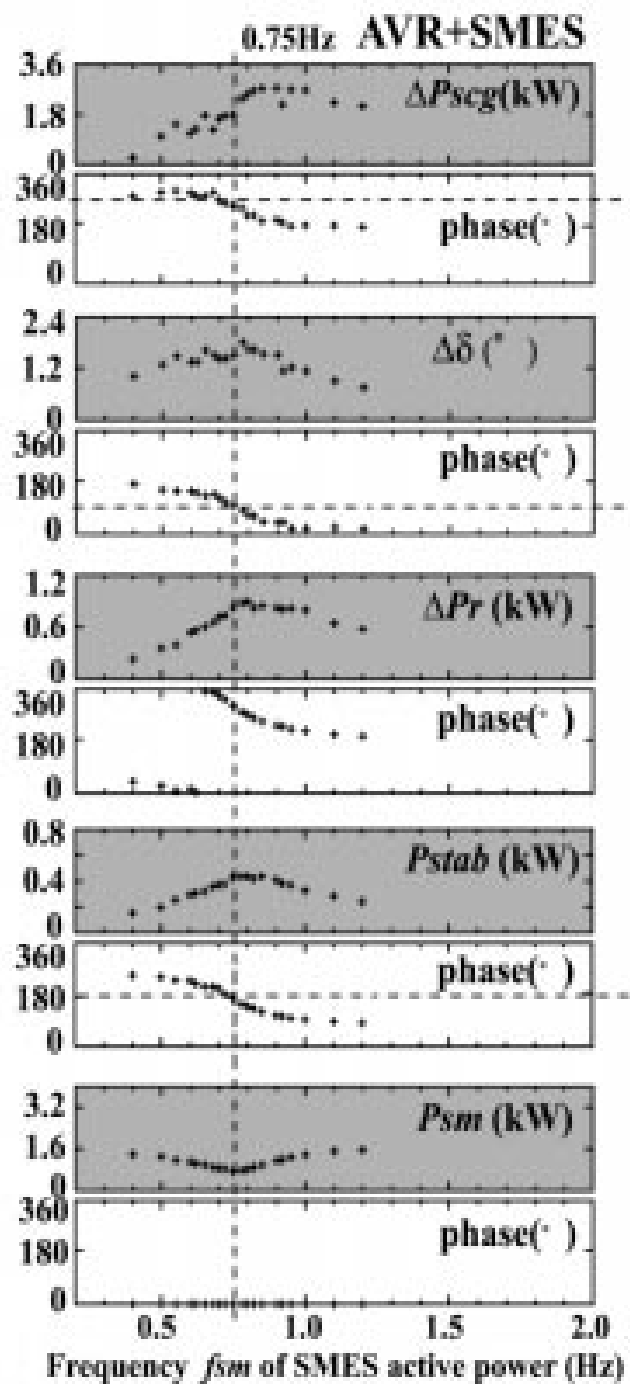

(b) with AVR and SMES stabilizing control

Fig. 5. Frequency characteristics (amplitude and phase) of power swing with AVR and AVR + SMES stabilizing control.

\section{B. Power Stabilization Control of SMES}

The frequency characteristics of the power oscillation due to the small SMES power disturbance with [AVR] and with [AVR+ SMES power stabilizing control] are shown in Fig. 5(a) and (b), respectively. The amplitude and phase of $\Delta P_{s c g}, \Delta \delta, \Delta P_{r}, P_{s m}$ and $P_{s t a b}$ signal are shown for the frequency $f_{s m}$ of SMES active power. The natural frequency $0.75 \mathrm{~Hz}$ does not change by [SMES power stabilizing control], however, the amplitude of $\Delta P_{s c g}, \Delta \delta$ decreases almost a half of those with only [AVR]-control. It is pointed out that the [SMES power-stabilizing control] can improve the damping of the system without reducing synchronizing force.

The phase difference between the deviation $\Delta P_{r}$ of the exciter power and $P_{s m}$ at the natural frequency is about -90 degrees. This means that the exciter power due to the [AVR]-control accelerates the power oscillation and reduces the damping force of the system.

\section{PSS Control}

The frequency characteristics of the power oscillation due to the small SMES power disturbance with [AVR + PSS] are shown in Fig. 6(a). The amplitude and phase of $\Delta P_{\text {scg }}, \Delta \delta, \Delta P_{r}, P_{s m}$, PSS signal are shown for the frequency $f_{s m}$ of SMES active power. The amplitude of $\Delta P_{s c g}$ becomes one-third of that with [AVR]-control. The [PSS]-control increases the damping force of the system. Comparing the phase characteristics of $\Delta P_{r}$ in Fig. 6(a) with that of Fig. 5(a) and (b), the phase difference between $\Delta P_{r}$ and $P_{s m}$ is shifted from -90 degrees to 10 degrees by the [PSS]-control. It can be pointed out that the [PSS]-control compensates the negative damping of the [AVR]-control, and then, the exciter power $P_{r}$ is effectively used to stabilize the power system oscillation. The natural frequency changes from $0.75 \mathrm{~Hz}$ to $0.71 \mathrm{~Hz}$. The synchronizing force is reduced a little by the [PSS]-control.

The frequency characteristics of the power oscillation with [AVR + PSS + SMES-stabilizing-control] 


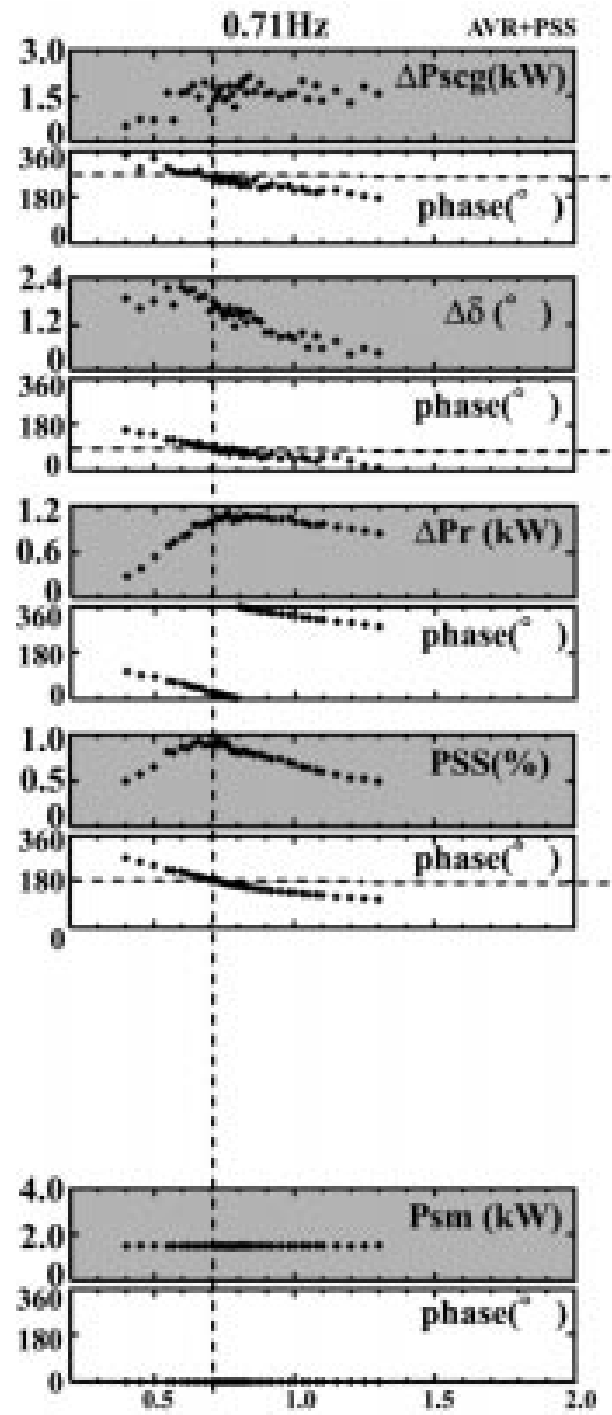

Frequency fsm of SMES active power $(\mathrm{Hz})$ (a) with AVR + PSS
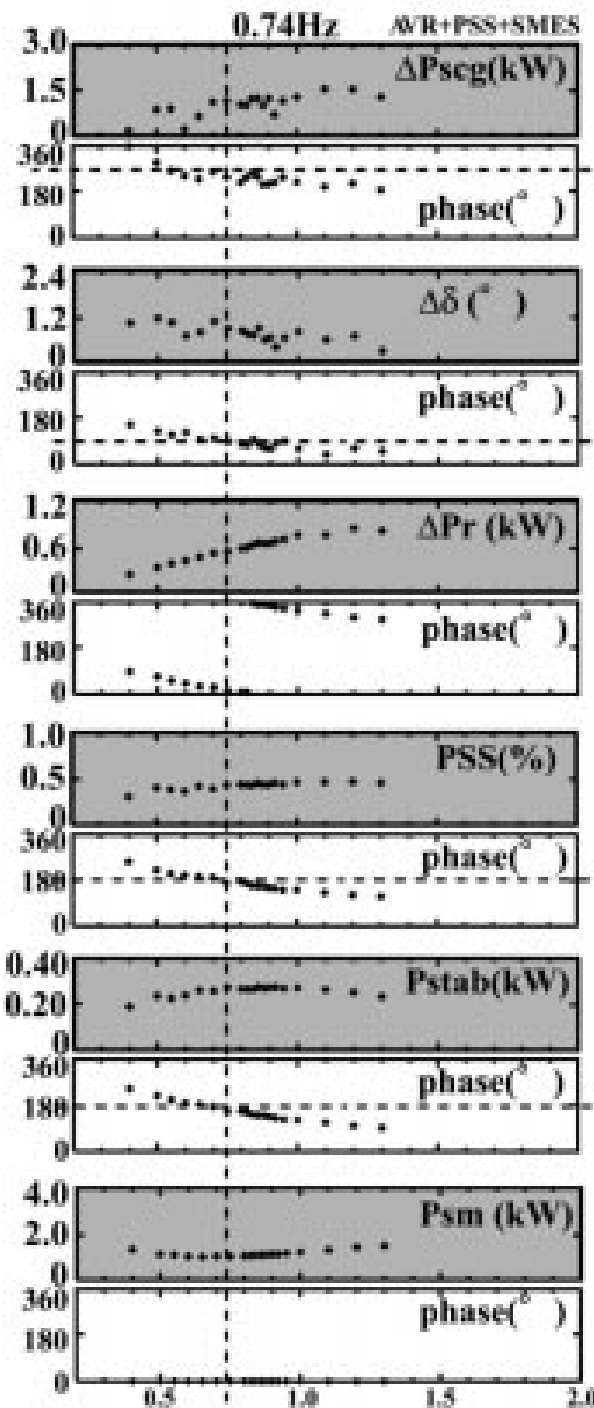

Frequeney fsm of SMES active power $(\mathrm{Hz})$

(b) with AVR + PSS and SMES stabilizing control

Fig. 6. Frequency characteristics (amplitude and phase) of power swing with [AVR + PSS] and [AVR + PSS + SMES] control.

are shown in Fig. 6(b). The amplitude and phase of $\Delta P_{\text {scg }}, \Delta \delta, \Delta P_{r}, P_{s m}, P_{\text {stab }}$, PSS signal are shown for the frequency $f_{s m}$. The power oscillation is damped without any bad interference among these control schemes.

\section{CONCLUSION}

Parallel running operation of $100 \mathrm{kVA}$ Superconducting Generator with high response excitation and 0.4 MJ SMES was carried out. The exciter controller (AVR and PSS) for high response excitation is designed taking the exciter power change at the excitation into account to improve the system stability. The SMES can also improve the power system stability.

The designed control functions of AVR, PSS and SMES were evaluated by use of SMES. The system response due to the SMES power modulation were observed and analyzed. Frequency characteristics of the designed control functions were obtained from on-line data of the system. The results obtained are as follows:

1) Natural frequency of the system including the control units is obtained from on-line data.

2) Synchronous and damping forces of the system are estimated experimentally.

3) [AVR]-control increases the synchronous force but reduces the damping force.

4) [SMES power stabilizing control] can improve the damping of the system without reducing the synchronizing force.

5) [PSS]-control is the most effective in increasing damping force and it reduces the synchronizing force a little. The experimental result shows that the [PSS]-control adjust the phase of exciter power so as to improve the system stability.

The system stability of parallel running of the SCG and the SMES is evaluated by use of SMES power control unit. 


\section{ACKNOWLEDGMENT}

The authors would like to thank all co-leagues of superconducting group in KEPCO and all members of our laboratory for their great help in the experiments.

\section{REFERENCES}

[1] J. L. Smith, Jr., "Overviews of the development of superconducting synchronous generators," IEEE Trans. Magn., vol. MAG-19, no. 3, pp. 522-528, May 1983.

[2] M. A. A. S. Alyan, Y. H. A. Rahim, and S. M. Osheba, "Assessment of steady state stability of a multi-machine power system with and without a superconducting alternator," IEEE Trans. Power Systems, vol. 5, no. 3, pp. 730-736, Aug. 1990.
[3] T. Nitta, T. Okada, S. Hayashi, M. Tari, and M. Kumagai, "Some considerations on superconducting generator with high response excitation through detail design of experimental 100 kVA generator," in Proc. 12th Int. Cryogenic Conf., 1988, pp. 768-772.

[4] T. Okada, T. Nitta, S. Hayashi, K. Saikawa, M. Tari, and M. Kumagai, "Design and manufacture of superconducting generator with high-response excitation," in Proc. 11th Int. Conf. Magnet Technology, 1989, pp. 562-567.

[5] T. Nitta, T. Okada, Y. Shirai, T. Kishida, Y. Ogawa, H. Hasegawa, K. Takagi, and H. Matsumoto, "Experimental studies on power system stability by high response excitation of a superconducting generator," IEEE Trans. Power Systems, vol. 12, no. 2, pp. 906-912, May 1997.

[6] T. Nitta, Y. Shirai, and T. Kishida, "Experimental studies on field circuit of superconducting generator," IEEE Trans. Appl. Superconduct., vol. 7 , no. 2, pp. 539-542, June 1997.

[7] T. Kishida, A. Izumi, and T. Koike, "Study of toroidal-SMES for power system stabilization," in Applied Superconductivity 96, 1996.

[8] T. Nitta, S. Mohri, Y. Shirai, H. Taniguchi, Y. Kitauchi, Y. Morioka, an K. Kawada, "Experimental study on on-line grasp of operating condition of longitudinal power system by use of SMES," IEEE Trans. Appl. Superconduct., vol. 11, no. 1, pp. 1294-1297, Mar. 2001. 